

F. Qureshi,

K. P. Draviaraj,

D. Stanley

From Shoulder and

Elbow Unit,

Northern General

Hospital, Sheffield,

United Kingdom

\title{
The Kudo 5 total elbow replacement in the treatment of the rheumatoid elbow
}

\author{
RESULTS AT A MINIMUM OF TEN YEARS
}

F. Qureshi,

FRCS(Trauma\&Orth),

Consultant Orthopaedic

Surgeon

Doncaster Royal Infirmary,

Armthorpe Road, Doncaster

DN2 5LT, UK.

K. P. Draviaraj, DipOrth,

FRCS(Trauma\&Orth), Shoulder

and Elbow Fellow

D. Stanley,

FRCS(Trauma\&Orth),

Consultant Shoulder and Elbow

Surgeon

The Shoulder and Elbow Unit

The Northern General Hospital

Sheffield Teaching Hospital

NHS Trust, Herries Road,

Sheffield S5 7AU, UK.

Correspondence should be sent

to $\mathrm{Mr}$ D. Stanley; e-mail:

Claire.faulkner@sth.nhs.uk

(C)2010 British Editorial Society of Bone and Joint Surgery doi:10.1302/0301-620X.92B10. $22476 \$ 2.00$

$J$ Bone Joint Surg [Br] 2010;92-B:1416-21.

Received 17 February 2010;

Accepted after revision 7 May

2010

\begin{abstract}
Between September 1993 and September 1996, we performed 34 Kudo 5 total elbow replacements in 31 rheumatoid patients. All 22 surviving patients were reviewed at a mean of 11.9 years (10 to 14 ). Their mean age was 56 years (37 to 78 ) at the time of operation. All had Larsen grade IV or V rheumatoid changes on X-ray. Nine (three bilateral replacements and six unilateral) had died from unrelated causes. One who had died before ten years underwent revision for dislocation.

Of the 22 total elbow replacements reviewed six had required revision, four for aseptic loosening (one humeral and three ulnar) and two for infection. Post-operatively, one patient had neuropraxia of the ulnar nerve and one of the radial nerve. Two patients had valgus tilting of the ulnar component.

With revision as the endpoint, the mean survival time for the prosthesis was $\mathbf{1 1 . 3}$ years (95\% confidence interval ( 10 to 13 ) and the estimated survival of the prosthesis at 12 years according to Kaplan-Meier survival analysis was $74 \%$ (95\% confidence interval 0.53 to 0.91 ).

Of the 16 surviving implants, ten were free from pain, four had mild pain and two moderate. The mean arc of flexion/extension of the elbow was $106^{\circ}\left(65^{\circ}\right.$ to $\left.130^{\circ}\right)$ with pronation/supination of $90^{\circ}\left(30^{\circ}\right.$ to $\left.150^{\circ}\right)$ with the joint at $90^{\circ}$ of flexion. The mean Mayo elbow performance score was 82 (60 to 100) with five excellent, ten good and one fair result.

Good long-term results can be expected using the Kudo 5 total elbow replacement in patients with rheumatoid disease, with a low incidence of loosening of the components.
\end{abstract}

Modern designs of total elbow replacement (TER) are either linked ${ }^{1-3}$ or unlinked ${ }^{4-6}$ with some having the ability to be inserted in either capacity, the so-called convertible prostheses. ${ }^{7,8}$ Although all modern prostheses reduce pain and improve function, the long-term outcomes are less clear with few peer-reviewed reports in the literature. ${ }^{1,9,12}$

Gill and Morrey ${ }^{1}$ published their experience of the Coonrad-Morrey linked TER (Zimmer, Warsaw, Indiana) in rheumatoid patients with a follow-up of ten to 15 years and Gschwend et $\mathrm{al}^{9}$ described the long-term results of the GSB III linked prosthesis. More recently, Tanaka et $\mathrm{al}^{10}$ have recorded their experience with the unlinked Kudo 5 (Biomet UK Ltd, Swindon, United Kingdom) prosthesis with a mean follow-up of 11.5 years, and Aldridge et $\mathrm{al}^{11}$ have published their survival analysis of the Coonrad/Coonrad-Morrey prosthesis at ten to 31 years. These long-term studies, however, are from orthopaedic units where the prostheses were developed and as such may not be representative of results achieved elsewhere.
In order to determine whether our experience of the Kudo 5 TER in the treatment of end-stage rheumatoid arthritis of the elbow was consistent with that reported by Kudo himself, we have retrospectively reviewed all our patients with a minimum follow-up of ten years. We used revision for any reason as the endpoint to analyse the survival of the implant in the 22 patients.

\section{Patients and Methods}

Between September 1993 and September 1999 we performed 34 Kudo 5 TERs on a consecutive series of 31 rheumatoid patients. At a minimum follow-up of ten years nine patients (three with bilateral replacements and six with unilateral) had died from unrelated causes leaving 22 surviving patients. There were 20 women and two men with a mean age at the time of TER of 56 years (37 to 78). All underwent a clinical and radiological review. Each was independently assessed by a surgeon who had not been involved in the initial procedure (FQ, KPD). All the patients had a radiological grade of IV or $\mathrm{V}$ according to the criteria of 
Table I. Details of the 22 surviving patients and their results

\begin{tabular}{|c|c|c|c|c|c|c|c|c|c|}
\hline Case & Gender & $\begin{array}{l}\text { Age } \\
\text { (yrs) }\end{array}$ & $\begin{array}{l}\text { Follow-up } \\
\text { (mths) }\end{array}$ & Side & $\begin{array}{l}\text { Range of flexion/extension } \\
\left({ }^{\circ}\right)\end{array}$ & Pain & $\begin{array}{l}\text { Mayo } \\
\text { score }\end{array}$ & Revision & $\begin{array}{l}\text { Time to failure } \\
\text { (mths) }\end{array}$ \\
\hline 1 & $\mathrm{~F}$ & 41 & 161 & $\mathrm{R}$ & 26 to 150 & None & 95 & - & \\
\hline 2 & $\mathrm{~F}$ & 41 & 132 & $\mathrm{~L}$ & - & & - & Loose ulna & 132 \\
\hline 3 & $\mathrm{~F}$ & 53 & 156 & $\mathrm{R}$ & - & & - & Loose humerus & 96 \\
\hline 4 & $\mathrm{~F}$ & 46 & 149 & $\mathrm{R}$ & 30 to 140 & None & 90 & & \\
\hline 5 & $\mathrm{~F}$ & 43 & 156 & $\mathrm{R}$ & 30 to 140 & None & 100 & & \\
\hline 6 & $\mathrm{~F}$ & 67 & 145 & $\mathrm{~L}$ & 10 to 140 & Mild & 80 & & \\
\hline 7 & $\mathrm{~F}$ & 37 & 146 & $\mathrm{R}$ & 30 to 120 & None & 80 & & \\
\hline 8 & $\mathrm{~F}$ & 66 & 152 & $\mathrm{~L}$ & 20 to 140 & None & 95 & & \\
\hline 9 & $\mathrm{~F}$ & 65 & 150 & $\mathrm{~L}$ & 20 to 140 & Moderate & 70 & & \\
\hline 10 & $\mathrm{~F}$ & 72 & 148 & $L$ & 30 to 120 & None & 80 & & \\
\hline 11 & $\mathrm{~F}$ & 51 & 152 & $\mathrm{R}$ & - & & - & Loose ulna & 72 \\
\hline 12 & $\mathrm{~F}$ & 72 & 146 & $L$ & 30 to 140 & Mild & 70 & & \\
\hline 13 & $\mathrm{~F}$ & 64 & 146 & $L$ & 30 to 130 & Moderate & 60 & & \\
\hline 14 & $\mathrm{~F}$ & 63 & 154 & $L$ & - & & - & Loose ulna & 36 \\
\hline 15 & $\mathrm{~F}$ & 58 & 141 & $\mathrm{R}$ & 45 to 110 & Mild & 70 & & \\
\hline 16 & $\mathrm{~F}$ & 68 & 142 & $L$ & 20 to 120 & None & 95 & & \\
\hline 17 & $\mathrm{~F}$ & 54 & 133 & $\mathrm{R}$ & 20 to 120 & None & 80 & & \\
\hline 18 & $\mathrm{~F}$ & 53 & 135 & $\mathrm{R}$ & 30 to 120 & None & 80 & & \\
\hline 19 & $\mathrm{M}$ & 78 & 139 & $L$ & 20 to 140 & Mild & 80 & & \\
\hline 20 & $\mathrm{~F}$ & 44 & 142 & $\mathrm{R}$ & - & & - & Infected & 12 \\
\hline 21 & $\mathrm{~F}$ & 61 & 127 & $L$ & - & & - & Infected & 108 \\
\hline 22 & $\mathrm{M}$ & 41 & 120 & $\mathrm{R}$ & 20 to 140 & None & 85 & & \\
\hline
\end{tabular}

Larsen, Dale and Eek $^{13}$ and met the diagnostic criteria of the American Rheumatism Association. ${ }^{14}$ The indication for surgery was intractable pain and to loss of function. There were no exclusion criteria.

At a mean follow-up period of 11.9 years (10.0 to 14.0$)$ clinical review was undertaken using the Mayo elbow performance score, ${ }^{15}$ and anteroposterior (AP) and lateral radiographs were taken to determine failure of the implant.

A life-table was constructed and a Kaplan-Meier survival analysis performed using revision for any cause as the endpoint.

Operative technique. All TERs were performed or supervised by the senior author (DS). A posterior triceps reflecting approach was used initially, ${ }^{16}$ but was then modified to allow decompression of the ulnar nerve without anterior transposition. ${ }^{17}$ This change was instituted as the senior author felt that there was less risk of ulnar nerve complications with simple decompression and anterior transposition.

Bony preparation of the humerus and ulna was undertaken as described by Tanaka et al. ${ }^{10}$ The collateral ligaments were only released to achieve soft-tissue balancing so that when the trial components were inserted the elbow could be flexed and extended without instability. If released they were not routinely repaired. Plugs prepared from the resected bone were inserted into the humeral shaft as a cement restrictor. Cement restriction was not used in the ulna. The humeral and metal-backed ulnar components were then sequentially inserted with Palacos cement (Heraeus Medical GmbH, Wehrheim, Germany) using a cement gun.
Post-operatively, the elbow was rested in an above-elbow backslab in extension for four days followed by active mobilisation. No splints or braces were used.

\section{Results}

We were unable to obtain data relating to the nine patients who died, partly because of the interval between death and the time of the review. In addition, in 2004 our institution changed computer systems and the records and radiographs of patients who had already died at that time had been destroyed.

However, we could identify the date of death and cross check this against the date of the TER in order to determine if the implant had been revised. Using this approach we were able to identify one patient who had undergone a revision for dislocation.

The details and Mayo performance scores of the 22 patients reviewed are shown in Table I. Of the 16 surviving arthroplasties, ten elbows were free from pain, four had mild pain and two moderate. The mean arc of flexion/ extension was $106^{\circ}\left(65^{\circ}\right.$ to $\left.130^{\circ}\right)$ and pronation/supination was $90^{\circ}\left(30^{\circ}\right.$ to $\left.150^{\circ}\right)$ with the elbow at $90^{\circ}$ of flexion. The mean Mayo Elbow Performance score was 82 (60 to 100) with five excellent, ten good and one fair result.

Survival analysis was determined for the 22 patients with revision for any cause as the endpoint. The mean survival time was 11.3 years $(95 \%$ confidence interval (CI 10 to 13 ) and the estimated survival of the prosthesis of 12 years according to Kaplan-Meier was $74 \%$ (95\% CI 0.53 to 0.91) (Fig. 1). 


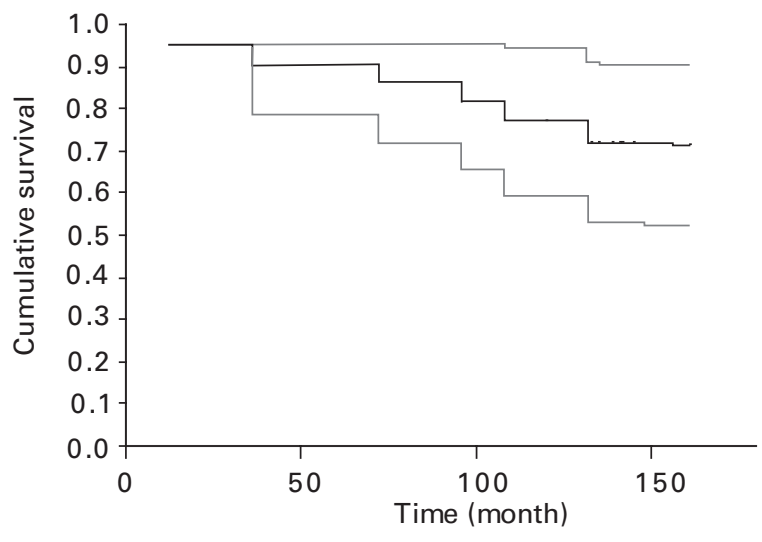

Fig. 1

Kaplan-Meier survival analysis using revision as the endpoint.



Fig. 2a

Fig. 2b

Anteroposterior a) and lateral b) radiographs at follow-up at ten years showing good alignment of both components and no evidence of loosening.



Fig. 3a



Fig. 3b



Fig. 3c

Case 3. A 53-year-old woman with humeral loosening. Progressive loosening is seen on sequential lateral radiographs taken at a) 13 months, b) 62 months and c) 96 months post-operatively.

Complications. Six patients had a revision procedure, in three for ulnar and in one for humeral aseptic loosening, and in two for infection. The mean time to revision was 6.3 years $(1.0$ to 11.0$)$. All the revision procedures were performed using the Coonrad-Morrey arthroplasty and, with the exception of the infected cases, were undertaken as a one-stage procedure. The two patients with infection were revised in two stages. Stage one involved removal of the implant and all of the cement together with the insertion of antibiotic beads. In stage two these were removed and the revision prosthesis inserted.

Post-operatively one patient had a neuropraxia of the ulnar nerve and another had a neuropraxia of the radial nerve. This patient was thin and we suspect that the neuropraxia may have resulted from pressure on the nerve by the tourniquet. Both recovered within six months of surgery.

There were no dislocations.

Radiological analysis. The radiographs of 12 patients were considered to be satisfactory with no evidence of loosening or valgus tilting (Fig. 2). Progressive radiolucent lines (measured on serial radiographs) $>1 \mathrm{~mm}$ wide were seen around one humeral (Fig. 3) and three ulnar components (Fig. 4). All of these patients had a revision procedure. Two patients had incomplete non-progressive radiolucent lines on the ulnar side of the joint which had remained unchanged since the time that the initial post-operative radiographs had 




Fig. $4 a$

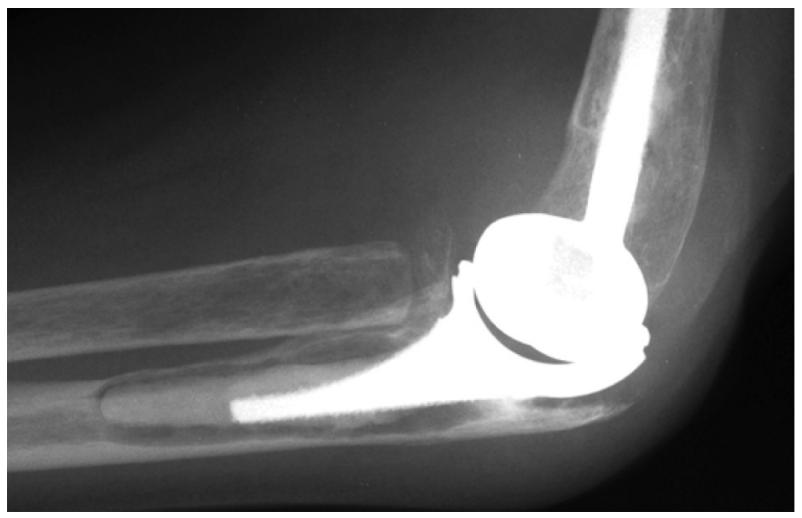

Fig. $4 b$

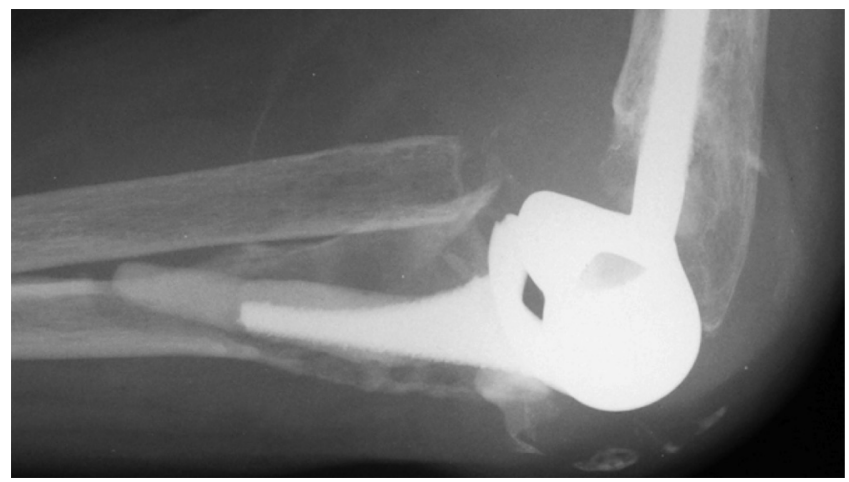

Fig. 4c

Case 11. A 51-year-old woman with ulnar loosening. Progressive loosening is seen on sequential lateral radiographs taken at a) 14 months, b) 62 months and c) 96 months post-operatively. This was the most common form of aseptic loosening seen in our study.

been taken. Valgus tilting of the ulnar component was present in two of the three TERs which underwent revision and at operation this was thought to be due to wear of the highdensity polyethylene of the ulnar component. In addition, valgus tilting was noted on two further AP radiographs (Fig. 5). At the time of review these patients were relatively asymptomatic, but have been under continuing review. They are currently not awaiting revision.

\section{Discussion}

In a comprehensive review of TER in the English-language literature Little, Graham and Carr, ${ }^{18}$ noted that of 3618 implantations the mean weighted follow-up was only 60 months. As such the long-term outcome of TER is unclear with few peer-reviewed reports in the literature. When long-term outcome studies have been published, 1,912,19 most have been at institutions where the prostheses were developed.

Gschwend et $\mathrm{al}^{9}$ using the GSB linked prosthesis reported survival of the implant of $87.7 \%$ at a mean follow-up of 13.5 years. Similar excellent results with linked arthroplasties have been reported by Gill and Morrey ${ }^{1}$ using the Coonrad-Morrey TER with a follow-up of ten to 15 years and by Aldridge et $\mathrm{al}^{11}$ who reported a survival analysis of the Coonrad/Coonrad-Morrey prosthesis of ten to 31 years.

Unlinked prostheses have also been reported to give good results with a number of studies reporting a survival of the Souter-Strathclyde prosthesis (Stryker UK, Newbury, United Kingdom) of five to ten years. ${ }^{4,5,12,19,20}$ Khatri and Stirrat ${ }^{4}$ using revision as the endpoint reported a survival of $75 \%$ at nine years while van der Lugt et $\mathrm{al}^{5}$ gave a survival rate of $77 \%$ at ten years. Trail et al, ${ }^{20}$ reported a survivorship of $87 \%$ at 12 years after the insertion of 186 SouterStrathclyde prostheses. They noted that $75 \%$ of the 24 revisions in their study were for humeral problems.

There are, however, fewer reports in the literature of the outcome of the Kudo TER. 6,10,21-26 Little et $\mathrm{al}^{26}$ compared the outcome of the Kudo prosthesis with that of the SouterStrathclyde and the Coonrad-Morrey implants at a followup of between 61 and 68 months. They found that all three implants had similar functional results in terms of relief from pain and range of movement and that, despite the Coonray-Morrey prosthesis having a linked mechanism, it 




Fig. 5

Case 2. Anteroposterior radiograph showing valgus tilting leading to point loading of the polyethylene surface of the ulnar component and wear.

did not have an increased risk of loosening. More recently a two-centre study of the Kudo 5 arthroplasty with a follow-up of two to 11 years suggested very encouraging functional results with survival of $86 \%$ of the implant at 100 months. ${ }^{27}$ Our own study with a follow-up of ten to 14 years, gives a survival of $74 \%$ at 12 years and suggests progressive failure with time. The results from both these studies, unfortunately, do not match those from the institution where the arthroplasty was developed.

Tanaka et $\mathrm{al}^{10}$ reported the long-term results of the Kudo type 5 TER and compared the outcome of all-polyethylene cemented ulnar component with that of the metal-backed cemented ulnar component. They found a survival rate of $100 \%$ at 13 years of the metal-backed ulnar component compared with only $72 \%$ with the all-polyethylene prosthesis $(\mathrm{p}=0.04)$.

Our study showed a mean survival time of 11.3 (95\% CI 10 to 13) years with a Kaplan-Meier survival analysis of $74 \%$ (95\% CI 0.53 to 0.91$)$. This difference in outcome compared with that obtained by Tanaka et $\mathrm{al}^{10}$ may be due to either minor differences in surgical technique or simply represents the differences which can be expected when surgery is performed by an implant designer compared with a regular TER user.

It should be noted that in our study three of the four revisions performed for aseptic loosening had loose ulnar components. This pattern of loosening is in contrast to that seen with early designs of TER in which humeral loosening was the cause of failure. The proximal tip of the humeral prosthesis classically migrated anteriorly with the axis moving posteriorly. This loosening pattern occurred as the result of the predominantly posteriorly-directed joint resultant force during flexion and extension of the elbow. The humeral component of the Souter-Strathclyde prosthesis migrates with external rotation with an anterior and varus tilt. ${ }^{28}$

There seems recently, however, to have been a shift in the pattern of aseptic loosening from the humeral to the ulnar component. ${ }^{6,11,13}$ This may in part be due to more accurate positioning of the humeral component such that the anatomical axis of movement is more closely replicated, but may also be related to the design of modern humeral prostheses. The early designs of TER achieved fixation of the humeral component either by having a humeral articulation which fitted over the remnant of the distal humerus or by the use of an intramedullary stem. In both situations, with or without the use of cement, there was essentially only one feature of the humeral design which helped to resist posteriorly-directed forces during flexion and extension. The modern linked and unlinked implants with the longest follow-up and lowest rates of humeral loosening have two methods of humeral fixation, stem and distal articular cover (Kudo, GSB) or stem and anterior flange (Coonrad-Morrey). The Souter-Strathclyde humeral prosthesis has small flanges which fit within the distal humerus and an intramedullary stem of variable length.

It would appear that an appropriate design and positioning of the humeral component are essential to reduce the risk of aseptic loosening. However, even if these criteria are met the risk does not appear to be eliminated. The increased frequency of loosening of the ulnar component which we and others have observed ${ }^{6,11}$ suggests that with a well-positioned and well-fixed humeral component the loosening forces are transmitted from the humeral to the ulnar side of the joint resulting in failure of the ulnar component. An explanation for this observation has recently been advanced by Cheung and O'Driscoll ${ }^{29}$ who identified pistoning of the ulnar component as a cause of loosening of the Coonrad-Morrey prosthesis. This same principle may also be the explanation for loosening of the ulnar component with other prostheses. They stated that to reduce the risk of this complication it is important to trim coronoid and olecranon osteophytes. ${ }^{29}$

Our experience suggests that good long-term results with a low incidence of loosening of the humeral and ulnar components can be expected when the Kudo 5 TER is used to treat rheumatoid disease of Larsen grade IV or grade $\mathrm{V} .{ }^{13}$ We would advise particular care when inserting both the trial and definitive components in order to be certain that there is no anterior impingement on flexion of the elbow or posterior impingement with extension. If this is not avoided pistoning of the ulnar component may occur with loosening of the implant.

No benefits in any form have been received or will be received from a commercial party related directly or indirectly to the subject of this article.

\section{References}

1. Gill DR, Morrey BF. The Coonrad-Morrey total elbow arthroplasty in patients who have rheumatoid arthritis: a ten to fifteen-year follow-up study. J Bone Joint Surg [Am] 1998;80-A:1327-35.

2. Gschwend N, Loehr J, Ivosevic-Radovanovic D, Sheier H, Muzinger U. Semiconstrained elbow prostheses with special reference to the GSB III prosthesis. Clin Orthop 1998;232:104-11. 
3. Hildebrand KA, Patterson SD, Regan WD, MacDermid JC, King GJ. Functional outcome of semiconstrained total elbow arthroplasty. J Bone Joint Surg [Am] 2000;82-A:1379-86

4. Khatri M, Stirrat AN. Souter-Strathclyde total elbow arthroplasty in rheumatoid arthritis: medium-term results. J Bone Joint Surg [Br] 2005;87-B:950-4.

5. van der Lugt JC, Geskus RB, Rozing PM. Primary Souter-Strathclyde total elbow prosthesis in rheumatoid arthritis. J Bone Joint Surg [Am] 2004;86-A:465-73.

6. Willems K, De Smet L. The Kudo total elbow arthroplasty in patients with rheumatoid arthritis. J Shoulder Elbow Surg 2004;13:542-7.

7. Gramstad GD, King GJ, O'Driscoll SW, Yamaguchi K. Elbow arthroplasty using a convertible implant. Tech Hand Up Extrem Surg 2005;9:153-63.

8. Bassi RS, Simmons D, Ali F, et al. Early results of the Acclaim elbow replacement. J Bone Joint Surg [Br] 2007;89-B:486-9.

9. Gschwend N, Scheier NH, Baehler AR. Long-term results of the GSB III elbow arthroplasty. J Bone Joint Surg [Br] 1999;81-B:1005-12.

10. Tanaka N, Sakahashi H, Ishii S, Kudo H. Comparison of two types of ulnar component in type-5 Kudo total elbow arthroplasty in patients with rheumatoid arthritis a long-term follow-up. J Bone Joint Surg [Br] 2006;88-B:341-4.

11. Aldridge JM 3rd, Lightdale NR, Mallon WJ, Coonrad RW. Total elbow arthroplasty with the Coonrad/Coonrad-Morrey prosthesis: a 10- to 31-year survival analysis. J Bone Joint Surg [Br] 2006;88-B:509-14.

12. Ikävalko M, Tiihonen R, Skyttä ET, Belt EA. Long-term survival of the SouterStrathcldye total elbow replacement in patients with rheumatoid arthritis. J Bone Joint Surg [Br] 2010;92-B:656-60.

13. Larsen A, Dale K, Eek M. Radiographic evaluation of rheumatoid arthritis and related conditions by standard reference films. Acta Radiol Diagn (Stockh) 1977;18:481-91.

14. Arnett FC, Edworthy SM, Bloch DA, et al. The American Rheumatism Association 1987 revised criteria for the classification of rheumatoid arthritis. Arthritis Rheum 1988;31:315-24.

15. Morrey BF, Adas RA. Semiconstrained arthroplasty for the treatment of rheumatoid arthritis of the elbow. J Bone Joint Surg [Am] 1992;74-A:479-90.

16. Bryan RS, Morrey BF. Extensive posterior exposure of the elbow: a triceps-sparing approach. Clin Orthop 1982;166:188-92.
17. Shahane SA, Stanley D. A posterior approach to the elbow joint. J Bone Joint Surg [Br] 1999;81-B:1020-2.

18. Little CP, Graham AJ, Carr AJ. Total elbow arthroplasty: a systematic review of the literature in the English language until the end of 2003. J Bone Joint Surg [Br] 2005;87-B:437-44.

19. Rozing P. Souter-Strathclyde total elbow arthroplasty. J Bone Joint Surg $[\mathrm{Br}]$ 2000;82-B:1129-34.

20. Trail IA, Nuttall D, Stanley JK. Survivorship and radiological analysis of the standard Souter-Strathclyde total elbow arthroplasty. J Bone Joint Surg [Br] 1999;81B:80-4

21. Potter D, Claydon P, Stanley D. Total elbow replacement using the Kudo prosthesis: clinical and radiological review with five- to seven-year follow-up. J Bone Joint Surg [Br] 2003;85-B:354-7.

22. Kudo H, Iwano K, Watanabe $\mathbf{S}$. Total replacement of the rheumatoid elbow with a hingeless prosthesis. J Bone Joint Surg [Am] 1980;62-A:277-85.

23. Kudo H, Iwano K. Total elbow arthroplasty with a non-constrained surface-replacement prosthesis in patients who have rheumatoid arthritis: a long-term follow-up study. J Bone Joint Surg [Am] 1990;72-A:355-62.

24. Kudo H, Iwano K, Nishino J. Cementless or hybrid total elbow arthroplasty with titanium-alloy implants: a study of interim clinical results and specific complications. J Arthroplasty 1994:9:269-78.

25. Kudo H, Iwano K, Nishino J. Total elbow arthroplasty with use of a nonconstrained humeral component inserted without cement in patients who have rheumatoid arthritis. J Bone Joint Surg [Am] 1999;81-A:1268-80.

26. Little CP, Graham AJ, Karatzas G, Woods DA, Carr AJ. Outcomes of total elbow arthroplasty for rheumatoid arthritis: comparative study of three implants. J Bone Joint Surg [Am] 2005;87-A:2439-48.

27. Thomas M, Adeeb M, Merisch I, Neumann L. Kudo 5 total elbow replacement in patients with rheumatoid arthritis: a two centre 2 year to 11 year follow-up study. Shoulder \& Elbow 2009;1:43-50

28. van der Lugt JC, Valstar ER, Witvoet-Braam, SW, Nelissen RG. Migration of the humeral component of the Souter-Strathclyde elbow prosthesis: a long-term RSA study. J Bone Joint Surg [Br] 2010;92-B:235-41.

29. Cheung EV, O'Driscoll SW. Total elbow prosthesis loosening caused by ulnar component pistoning. J Bone Joint Surg [Am] 2007;89-A:1269-74. 